\title{
A new actinopterygian Cheirolepis jonesi nov. sp. from the Givetian of Spitsbergen, Svalbard
}

\author{
Michael J. Newman ${ }^{1}$, Carole J. Burrow ${ }^{2}$, Jan L. den Blaauwen ${ }^{3} \&$ Sam Giles $^{4}$ \\ 'Vine Lodge, Vine Road, Johnston, Haverfordwest, Pembrokeshire, SA62 3NZ, UK. \\ ${ }^{2}$ Geosciences, Queensland Museum, 122 Gerler Road, Hendra, 4011 Queensland, Australia. \\ ${ }^{3}$ University of Amsterdam, Science Park 904, 1098 XH Amsterdam, The Netherlands. \\ ${ }^{4}$ School of Geography, Earth and Environmental Sciences, University of Birmingham, Birmingham, UK.
}

E-mail corresponding author (Michael J. Newman): ichthyman@btinternet.com

Keywords:

- Devonian

- Arctic

- Actinopterygii

- Marine

- Histology

Received:

23. September 2020

Accepted:

7. January 2021

Published online:

26. April 2021
Two specimens of a new early actinopterygian Cheirolepis jonesi nov. gen. et sp. have been collected from the lagoonal Middle Devonian (Givetian) Fiskekløfta Member, the upper member of the Tordalen Formation in the Mimerdalen Subgroup of Spitsbergen. This is the second oldest Cheirolepis species known from articulated remains. The holotype consists of an articulated head and the anterior trunk. The other specimen is an articulated skull which was 3D scanned to determine the internal structure and general architecture. The new taxon differs from other Cheirolepis species in the relative dimensions of the bones of the head, including a narrow anterior end of the dentary, longer accessory operculum and correspondingly shorter dermohyal, as well as a longer premaxilla and proportionally larger quadratojugal, and the organisation and relative size of the teeth.

\section{Introduction}

A new species of actinopterygian Cheirolepis jonesi sp. nov. is here described from the Middle Devonian (Givetian) of Mimerdalen in Spitsbergen, Svalbard. Previously, five species of Cheirolepis have been recognised as valid, three of which are known from articulated remains. These include the type species Cheirolepis trailli Agassiz, 1835 from the Eifelian of the Orcadian Basin of northern Scotland, Cheirolepis canadensis Whiteaves, 1881 from the Frasnian of Miguasha, eastern Canada and Cheirolepis schultzei Arratia \& Cloutier, 2004 from the uppermost Givetian of Red Hill, Nevada, USA (Schultze, 2010). Three further species Cheirolepis gaugeri Gross, 1973, Cheirolepis gracilis Gross, 1973 and Cheirolepis aleshkai Plax, 2020 from the Eifelian to Givetian of the Baltic Region (specifically Estonia and Belarus; Mark-Kurik, 2000; Plax, 2020) are represented by isolated scales. Previous mention of C. gaugeri and C. gracilis being present in German deposits (e.g., Pearson \& Westoll, 1979) are presumably due to mistranslations of the original German description by Gross (1973). Another species, Cheirolepis sinualis nomen nudum, from Belarus is undescribed with only the name published (Mark-Kurik, 2000). Giles et al. (2015) gave a short history of research on Cheirolepis in their study of the endoskeletal anatomy. Since then, further published work on the species $C$. canadensis has included microanatomical and histological studies of the post cranium (Zylberberg et al., 2016) and the teeth (Meunier et al., 2018).

Newman, M.J., Burrow, C.J., den Blaauwen, J.L. \& Giles, S. 2021: A new actinopterygian Cheirolepis jonesi nov. sp. from the Givetian of Spitsbergen, Svalbard. Norwegian Journal of Geology 101, 202103.

https://dx.doi.org/10.17850/njg101-1-3.

(C) Copyright the authors.

This work is licensed under a Creative Commons Attribution 4.0 International License. 
The new material was collected in 2018 from Estheriahaugen North in the hills above the abandoned Russian mining town of Pyramiden. Fossils (including the two partially articulated specimens of Cheirolepis jonesi described below) are mostly preserved in ironstone nodules found in a 30 metrethick, poorly stratified, brownish-black mudstone (Newman et al., 2020). Newman et al. (2020) considered the environment of deposition to be a backwater marine environment, most likely a lagoon. Certainly, there is a marine influence, although a lack of marine invertebrate species may indicate that the probable lagoon was part of an estuarine complex. The vast majority of specimens collected so far are fish, many of which are articulated and very large (up to a metre in length). The fauna collected recently (by MJN and his fellow fieldworkers - see acknowledgements) includes psammosteids, large osteostracans, acanthodians, antiarchs, arthrodires, sarcopterygians (including at least two species of coelacanth), tetrapodamorphs and of course actinopterygians. Most of the species are new and number around 20 different forms. One species of biogeographic importance is the acanthodian Cheiracanthus intricatus which was recently described by Newman et al. (2019). This species is also found in the marginal marine environment of the Baltic Region where its range starts earlier, in the Eifelian. The species also probably occurs in the Givetian of Belarus (Newman et al., 2019). This implies a marine connection between these areas and Spitsbergen at certain times. The geology and depositional environment are described in detail by Newman et al. $(2019,2020)$.

\section{Materials and methods}

Two specimens (PMO 235.120 the holotype, and paratype PMO 235.121, both in the palaeontological collections of the Natural History Museum at the University of Oslo) were available for study (Fig. 1). The material is not suitable for chemical preparation, so only mechanical preparation was done on the specimens. Macro photographs were taken using a Canon EOS 450. Small fragments of squamation and a fragment of the pectoral fin were broken off PMO 235.120 during preparation and imaged by CJB using an Hitachi Tabletop TM-1000 Environmental Scanning Electron Microscope (ESEM) at the Queensland Museum, Brisbane, Australia. Other fragments were thin-sectioned by JLdB using epoxy resin and various grain sizes of carborundum grinding powder down to 4 microns, with sections photographed using a Sony DSC-H2 camera on a Nikon Eclipse E400 microscope. CT scanning of PMO 235.121 was undertaken by SG at the Imaging and Analysis Centre, NHMUK, using a Metris X-Tek HMX ST 225 with the following settings: 3142 projections, 4 frames per projection, 1000 ms exposure, $200 \mathrm{kV}, 215 \mu \mathrm{A}, 1.6$ $\mathrm{mm}$ copper filter, voxel size $43.5 \mu \mathrm{m}$. Reconstructed tomographic datasets were segmented in Mimics v.19 (biomedical.materialise.com/mimics; Materialise, Leuven, Belgium). Images of the resulting models were then generated using Blender (blender.org). Raw data, the segmented Mimics file, and 3D PLY files are available at https://dx.doi.org/10.5281/zenodo.4431685.
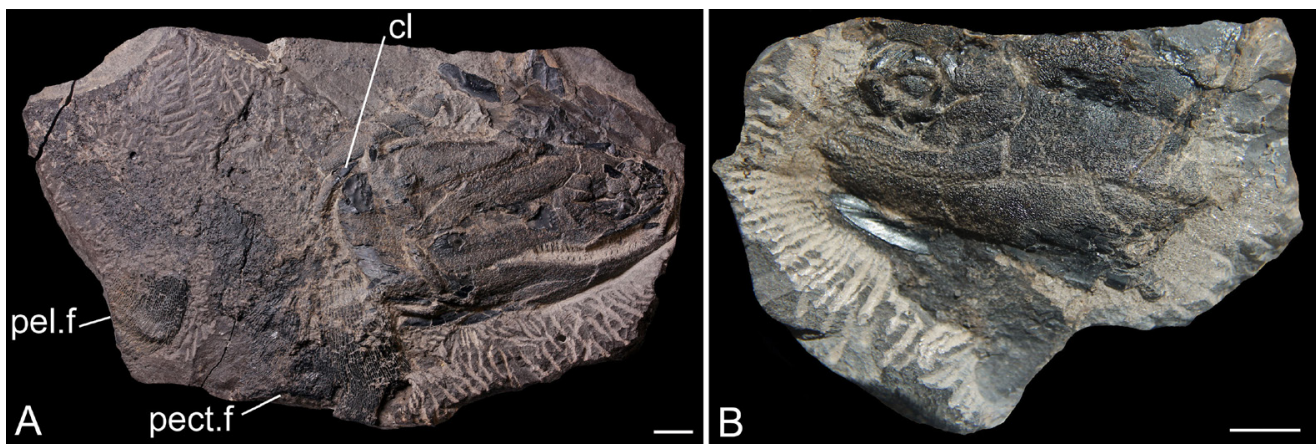

Figure 1. Cheirolepis jonesi from Estheriahaugen North. (A) PMO 235.120 the holotype preserving head and anterior part of post cranium. (B) PMO 235.121 the paratype preserving the head only. cl-cleithrum, pect.f-pectoral fin, pel.f - pelvic fin. Scale bar $=10 \mathrm{~mm}$. 


\title{
Systematic palaeontology
}

\author{
Class OSTEICHTHYES Huxley, 1880 \\ Subclass ACTINOPTERYGII Cope, 1887 \\ Family CHEIROLEPIDIDAE Pander, 1860 \\ Genus Cheirolepis Agassiz, 1835
}

Type species. - Cheirolepis trailli Agassiz, 1835

Included species. - Cheirolepis aleshkai Plax, 2020, Cheirolepis canadensis Whiteaves, 1881, Cheirolepis gaugeri Gross, 1973, Cheirolepis gracilis Gross, 1973, Cheirolepis jonesi sp. nov., Cheirolepis schultzei Arratia \& Cloutier, 2004.

Diagnosis. - Elongate fusiform actinopterygians with dermosphenotic sutured to supraorbitals and not to nasal. Independent preorbital present. Jugal with conspicuous notch in its orbital margin that produces an angle of about $90^{\circ}$ between dorsal and ventral rami. Teeth lack an acrodin cap. Fringing fulcra-like margin of all fins formed by swollen segments of lepidotrichia. Scales are micromeric and subrhombic, with crowns bearing ridges extending to the posterior margin, with minimal overlapping. Scales have a bone base, multi-layered ganoine, and wide dentinal canals. Modified after Arratia \& Cloutier (1996) and Schultze (2015).

Remarks. - The most obvious character common to all Cheirolepis species is the small rhombic scales.

Cheirolepis jonesi sp. nov.

Holotype. - PMO 235.120 and paratype PMO 235.121.

Derivation of name. - Named for Roger Jones of Wimbledon, London, one of the team that excavated Estheriahaugen North to yield the new fauna and who discovered the first remains of the species.

Diagnosis. - A Cheirolepis with a narrow snout; large dermohyal; dentary narrows markedly at the anterior end; an outer row of minute teeth and an inner row of moderately large teeth on both the maxilla and the dentary; relatively large quadratojugal located at the posterior dorsal corner of the maxilla; premaxilla long and narrow; skull bone ornamented with short ridges and tubercles interspersed with pore openings of the underlying pore canal network; otic canal without secondary branches; anterior edge of pelvic fin base is more than a head length posterior to the jaw articulation; flank scales are $0.5-0.7 \mathrm{~mm}$ wide with up to 15 sharp oblique ridges that converge posteriorly on larger scales.

Remarks. - Most of the features listed as diagnostic characters in the most recent diagnosis of a Cheirolepis species, Cheirolepis canadensis (Arratia \& Cloutier, 1996), are not distinguishable on Cheirolepis jonesi. There is no lateral branch of the otic canal, unlike in C. canadensis (Arratia \& Cloutier, 1996, p. 180, figs. 1A, 6B \& 9B) and Cheirolepis trailli (Pearson \& Westoll, 1979, p. 351, fig. 4E, G). There are only two rows of teeth in C. jonesi, as also reported for C. trailli, whereas Arratia \& Cloutier (1996, p. 182) observed that $C$. canadensis had "elongated teeth organized into one row and smaller teeth laterally, medially and in between the longer ones" on the maxilla. The position of the pelvic fin is similar to that in C. trailli, with both having a fin base that is notably shorter than in C. canadensis.

Material. - The holotype PMO 235.120 and the paratype PMO 235.121 are the only specimens confirmed to belong to the new species. 
Type locality and horizon. - Estheriahaugen North (Lat. $78^{\circ} 40^{\prime} \mathrm{N}$, Long. $16^{\circ} 13^{\prime} \mathrm{E}$ ) $3 \mathrm{~km}$ northeast of the abandoned Russian mining town of Pyramiden, Spitsbergen, Svalbard, in the Fiskeløfta Member of the Mimerdalen Subgroup (late Givetian).

Description:

General morphology. - The holotype (Fig. 1A), although only preserved anterior of the pelvic fins, indicates that the species was long and slender. This is particularly noticeable with the head, which has a narrow snout. Like other species of Cheirolepis, the pelvic fin is close to the pectoral fin.

Head and branchial morphology. - The head of the holotype (Fig. 2) is preserved in right-lateral aspect. Some bones of the left side of the head are exposed in visceral view towards the top of the slab,
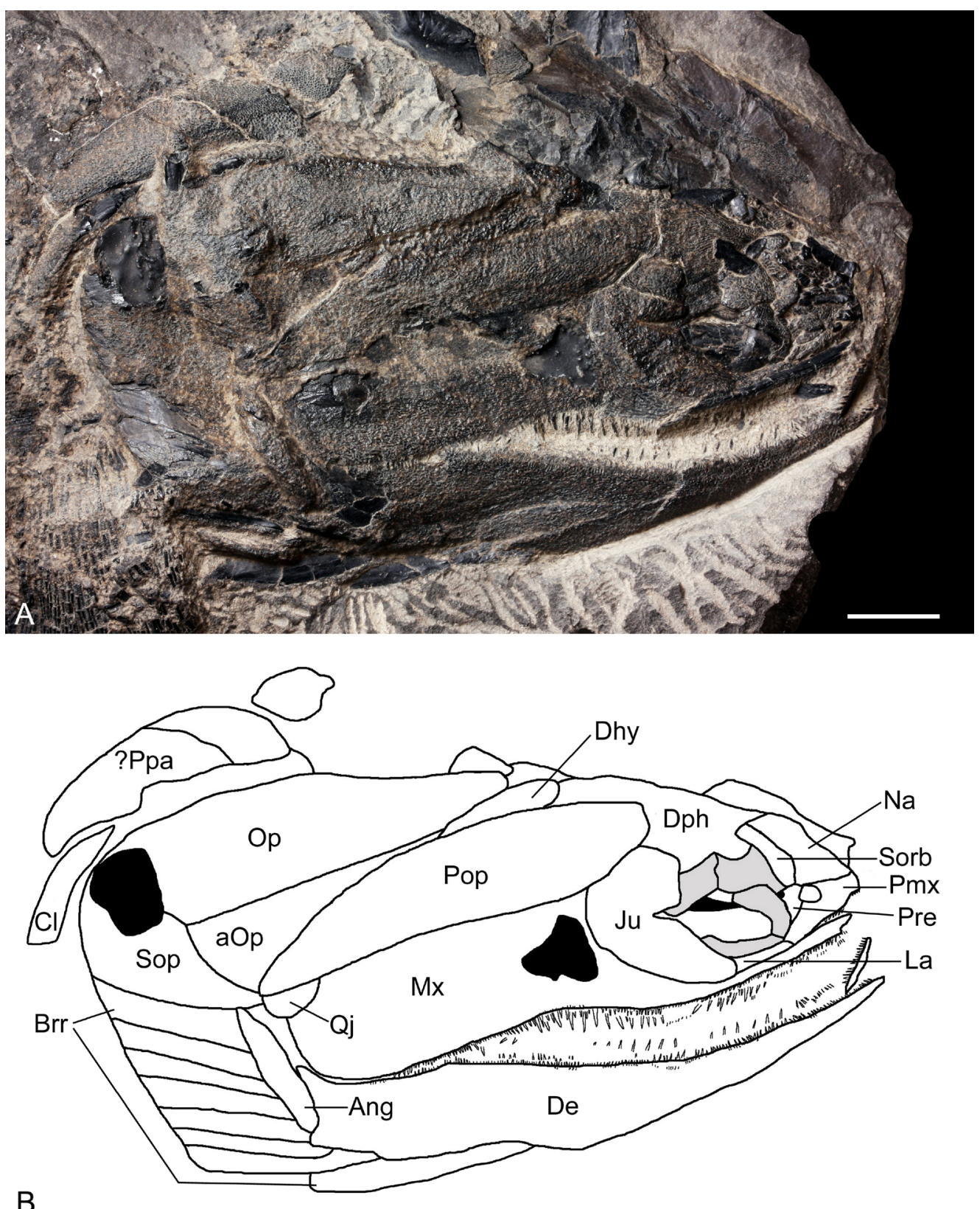

B

Figure 2. Cheirolepis jonesi PMO 235.120 the holotype from Estheriahaugen North. Head. The large, irregular black areas are filled in voids in the bone created when the slab was split. (A) photograph. (B) line drawing of the photograph, bonesshaded greyare thescleroticbones. Ang-angular, aOp-accessoryoperculum, Brr-branchiostegal rays, cl - cleithrum, De - dentary, Dhy - dermohyal, Dph - dermosphenotic, Ju - jugal, La - lacrimal, Mx - maxilla, $\mathrm{Na}$ - nasal bone, Op-operculum, Pmx - premaxilla, Pop - preoperculum, ?Ppa-postparietal, Pre - preorbital bone, Qj - quadratojugal, Sorb-supraorbital bones, Sop-suboperculum. Scale bar $=10 \mathrm{~mm}$. 
but they are not determinable at present. The head of the second specimen (Fig. 1B) is preserved in left-lateral aspect, and the right side of the head is preserved within the matrix (Fig. 3). No part of the neurocranium is visible in either specimen, and tomographs confirm that the endoskeleton is unmineralised across the specimen. The parietal plate is not preserved, but the postparietal appears to have been displaced posteriorly on the holotype, indicating some movement during decomposition. The plate is incomplete, so its dimensions are not determinable. The ornamentation of the bones is quite variable. All the bones including the sclerotic plates are ornamented with thin ridges that can
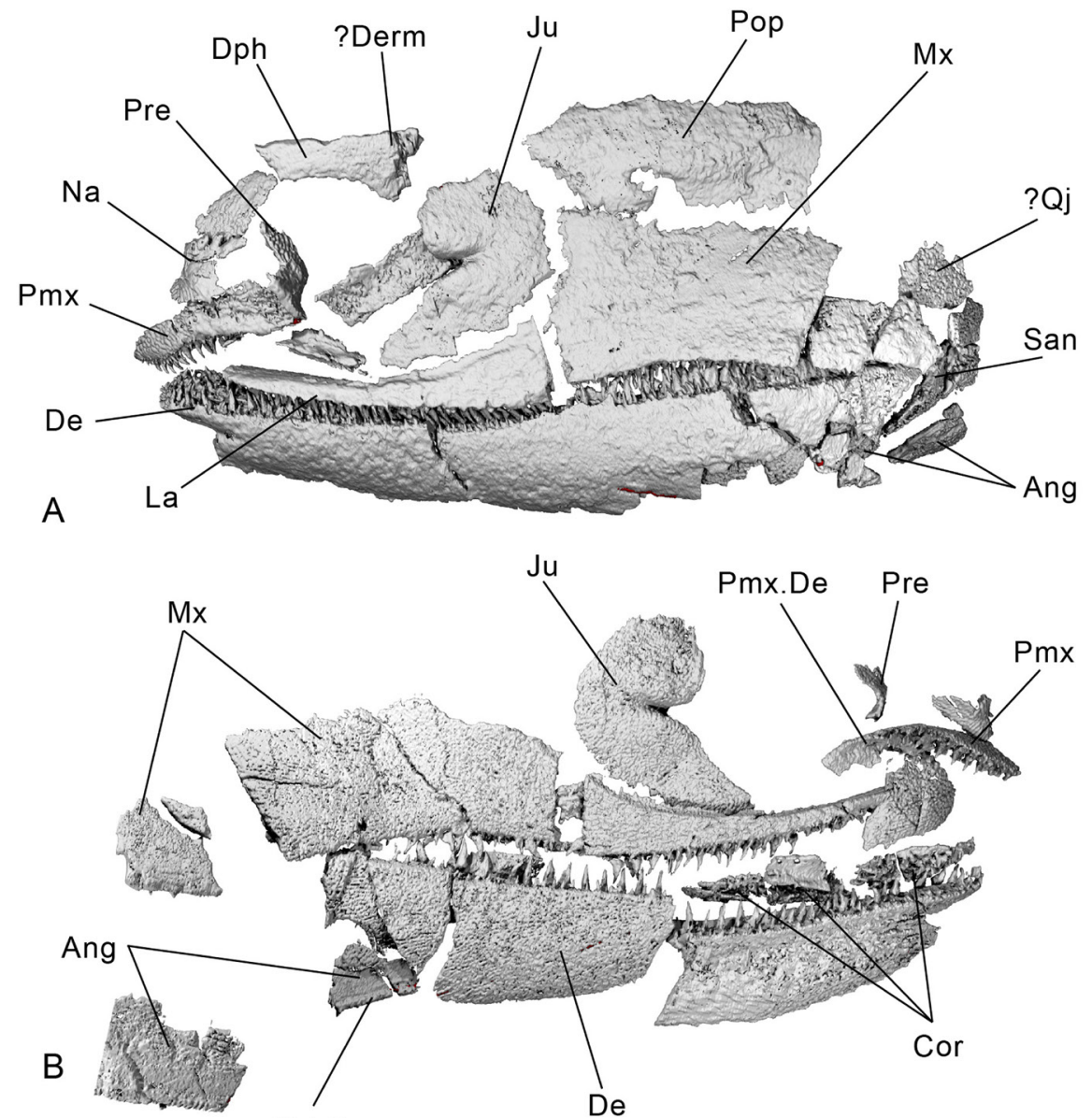

Md.C

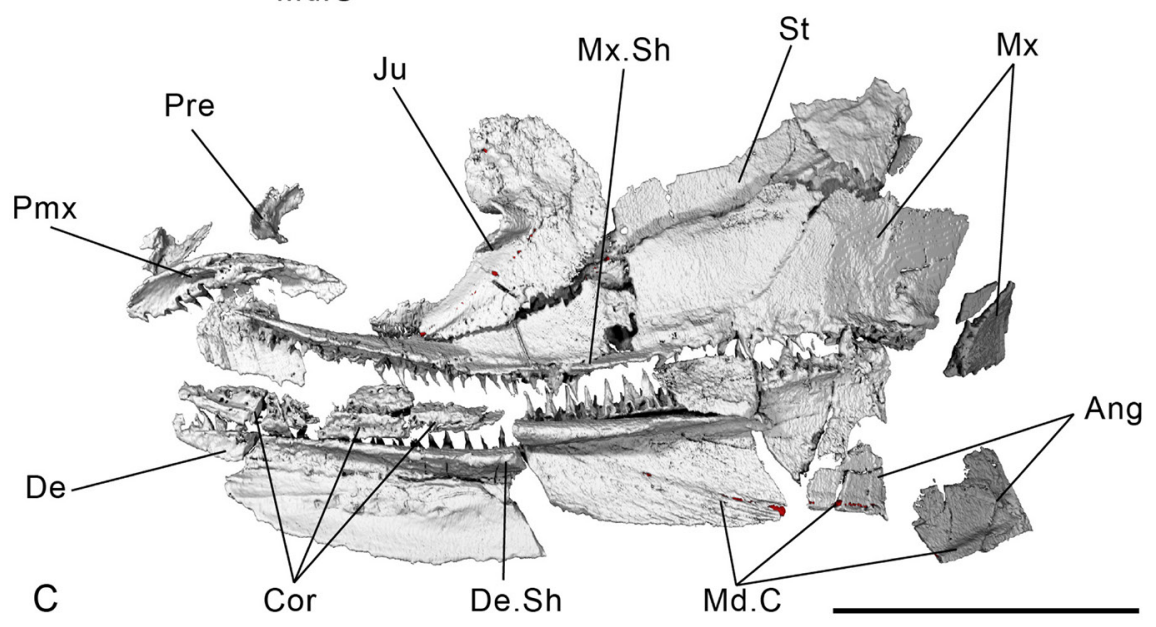

Figure 3. Cheirolepis jonesi PMO 235.121 the paratype from Estheriahaugen North. Three-dimensional render of cranial bones in (A) left lateral, (B) right lateral, and (C) right medial view. Displaced dermosphenotic and supratemporal not rendered. Ang - angular, Cor - coronoids, De - dentary, ?Derm - unidentified dermal bone, De.Sh - shelf on dentary, Dph - dermosphenotic, Ju - jugal, La - lacrimal, Md.C - mandibular canal, Mx maxilla, Mx.Sh - shelf on maxilla, Na-nasal bone, Pmx-premaxilla, Pmx.De-depression on premaxilla for maxilla, Pop - preoperculum, Pre - preorbital bone, ?Qj - possible quadratojugal, San - surangular, St - supratemporal. Scale bar $=20 \mathrm{~mm}$. 
run subparallel to plate edges (Fig. 4A) or are more sinuous (Fig. 4B). In certain areas, for example on the dentary (De), the ornament comprises very short ridges and tubercles (Fig. 4C). The ridges have an ornamentation of oblique, sharp ridges similar to those on the lepidotrichia (see below). One indeterminable bone (possibly part of the parietal) has an ornamentation of small tubercles (Fig. 4D). Sensory lines are difficult to identify on the surface of the bones as they often cannot be differentiated from breaks or sutures. Some of the sensory canals were identified from CT data analysis (Figs. 3 \& 5).

Rostral and orbital region. - The rostral area has a mosaic of small bones. As these have been displaced slightly and in places broken with some preserved in visceral aspect and others in external view, determining plate margins and sutures is difficult. The median middle postrostral bone is not identifiable, probably due to it being displaced. The premaxilla (Pmx), preorbital bone (Pre) and supraorbital bone (Sorb) are in situ around the anterior margin of the orbit. The premaxilla is rectangular, and in PMO 235.121 is roughly four times longer than deep (Figs. 3A \& 5A). Two rows of teeth are borne on a medial shelf near the ventral margin of the premaxilla: an inner row of up to 11 conical, recurved teeth, with a number of additional empty sockets; and an outer row of smaller, more numerous teeth, with fewer empty sockets. The dermal ornament also forms pointed, tooth-like projections along the labial margin. These continue on from the maxilla ( $\mathrm{Mx}$ ), the anterior tip of which rests in a shallow depression on the posterior fifth of the premaxillary shelf. The sensory canal enters the posterior margin of the premaxilla and terminates around halfway along the bone near its dorsal margin (Fig. 5J). The nasal bone ( $\mathrm{Na}$ ) is subrectangular and is located anterior to the thinner supraorbital, which contacts the upper two-thirds of the posterior edge of the nasal bone. The lower third of the posterior edge of the nasal bone is sutured to the preorbital bone. In PMO 235.121, the posterior margin of the
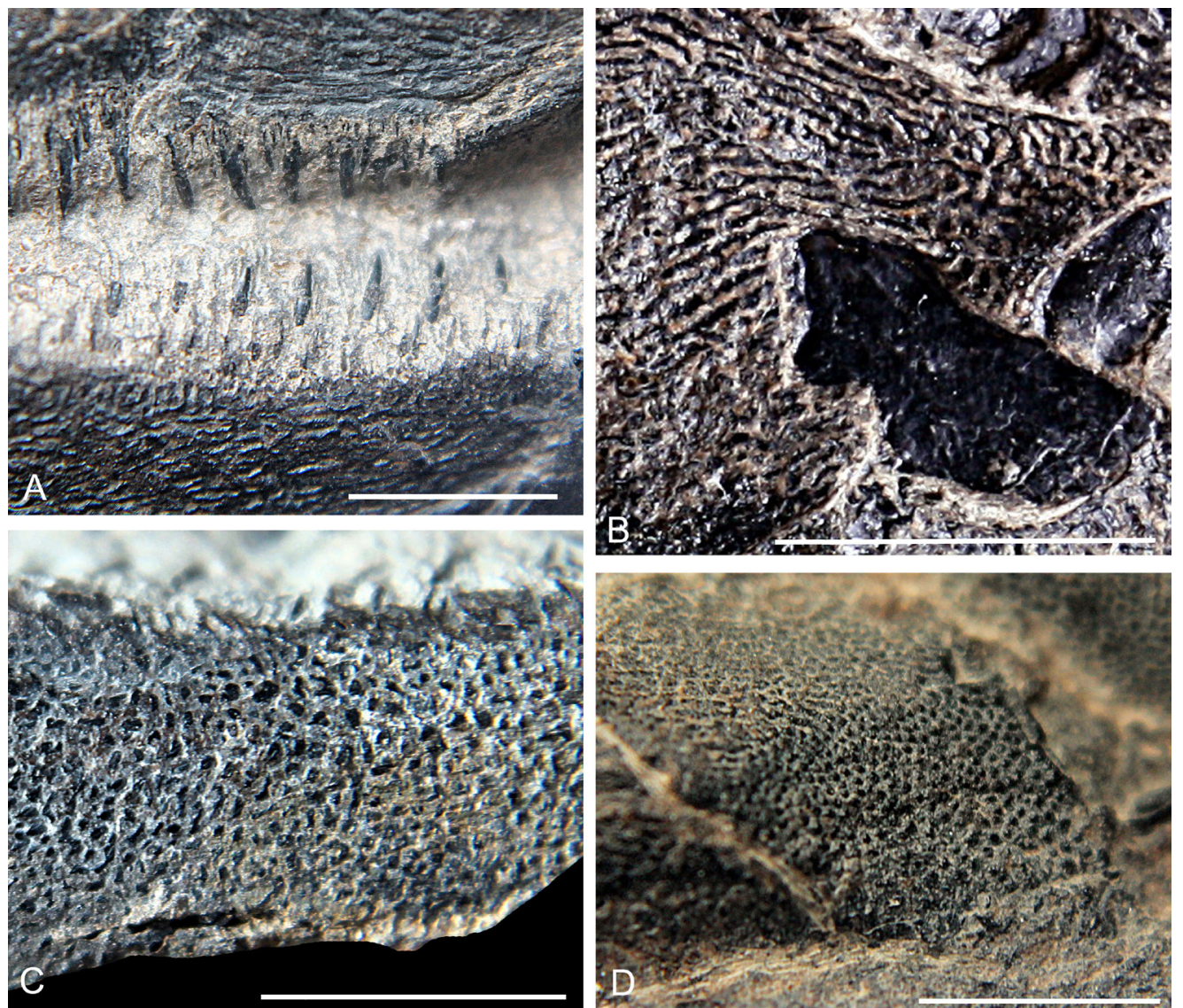

Figure 4. Cheirolepis jonesi PMO 235.120 the holotype from Estheriahaugen North. Ornamentation of the head plates. (A) ornament of posterior of jaws with straight ridges paralleling the occlusal surfaces, teeth partly buried in matrix. (B) sinuous ridge ornamentation on part of dermosphenotic. (C) short ridge and tubercle ornamentation on the anterior end of the dentary. (D) tubercle ornamentation on the possible postparietal. Scale bars $=5 \mathrm{~mm}$. 

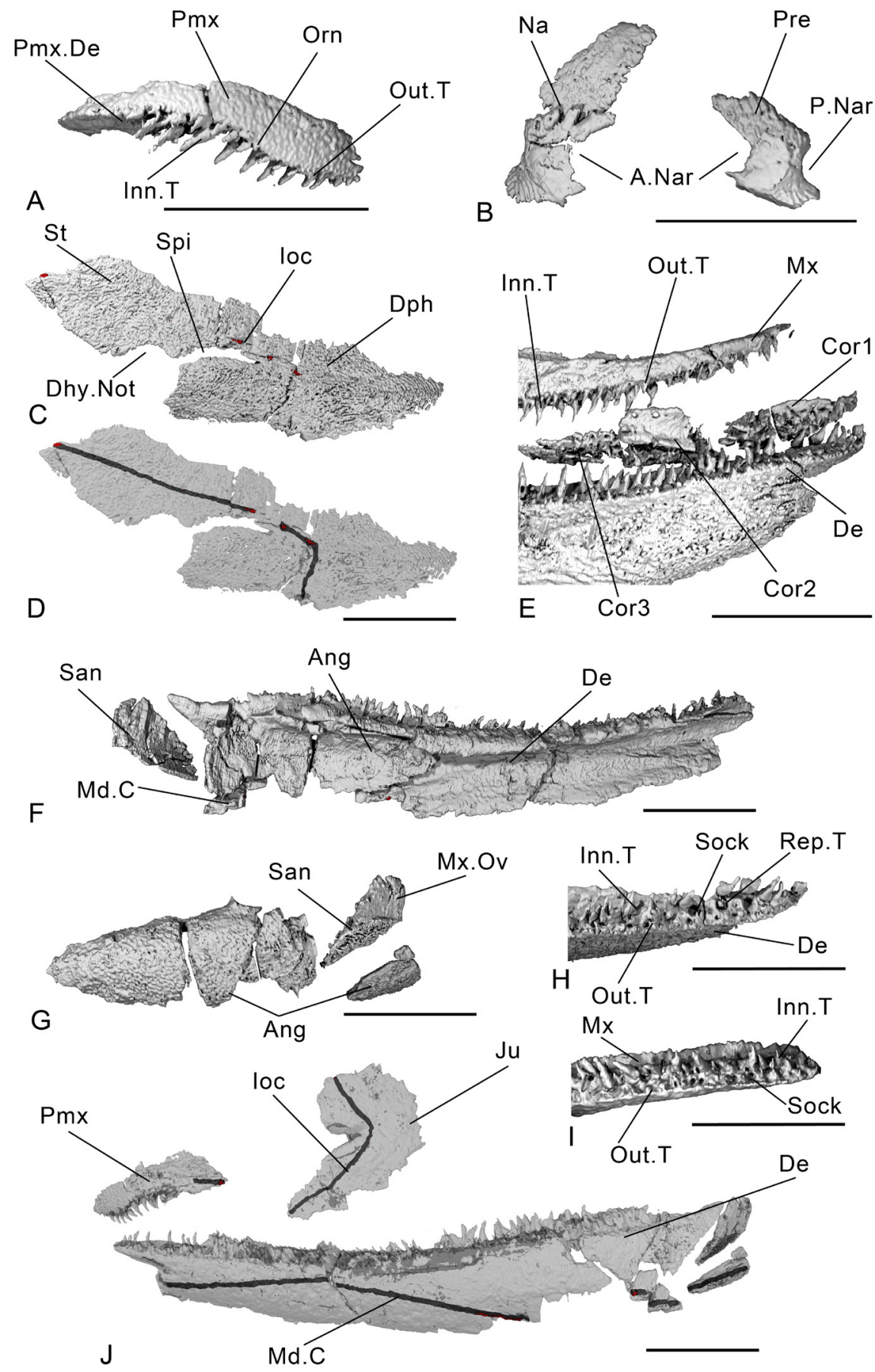

Figure 5. Three-dimensional renders of cranial anatomy in Cheirolepis jonesi PMO 235.121 the paratype from Estheriahaugen North. (A) right premaxilla in ventrolateral view. (B) left snout bones (not in life position). (C) render and (D) partially transparent render of right skull roofing bones. (E) right upper and lower jaws in lateral view showing displaced coronoids. (F) left lower jaw in medial view. (G) left infradentaries in lateral view. (H) right dentary in dorsolateral view. (I) left maxilla in ventolateral view. (J) partially transparent render of left canal-bearing bones of the cheek. A.Nar - anterior naris, Ang - angular, Cor1 - anterior coronoid, Cor2 - middle coronoid, Cor3 - posterior coronoid, De - dentary, Dhy.Not - notch for dermohyal, Dph-dermosphenotic, Inn.T-inner tooth row, loc-infraorbital canal, Ju - jugal, Md.C - mandibular canal, Mx - maxilla, Mx.Ov- maxillary overlap, Na - nasal bone, Orn -dermal ornament, $\rightarrow$ Out.T - outer tooth row, P.Nar - posterior naris, Pmx - premaxilla, Pmx.De - depression on premaxilla for maxilla, Pre - preorbital bone, Rep.T - replacement tooth, San - surangular, Sock - empty tooth socket, Spi - spiracle, St - supratemporal. Scale bars $=10 \mathrm{~mm}$. 
nasal bone can be seen to be excavated for the anterior naris (Fig. 5B). The preorbital bone is roughly triangular with its ventral edge sutured to the posterior apex of the premaxilla. The preorbital bone has a hole at its dorsoposterior margin which we interpret as the posterior naris. Because of the slight displacement of the rostral bones in the holotype it is unclear whether another pair of external nares is present as seen in Cheirolepis trailli. However, the preorbital in PMO 235.121 is notched for both the anterior and the posterior nares (Fig. 5B). The anterior apex of the premaxilla is sutured to the nasal bone. The lacrimal (La) is shallow and roughly $1 / 3$ of the length of the premaxilla, and is located between the premaxilla and the jugal (Ju), on the ventral margin of the orbit. The infraorbital canal appears to be carried along its ventral edge. The jugal is roughly L-shaped with a deep notch at the orbital margin as is usual for Cheirolepis, and carries the infraorbital canal along its entire length (Fig. 5J). The ventral portion below the notch is considerably longer than the posterodorsal part. The irregularly shaped dermosphenotic (Dph) forms the dorsal margin of the orbit (Fig. 5C). The anterior margin of the dermosphenotic is sutured to the nasal bone dorsally and the supraorbital ventrally, and to the anterodorsal margin of the jugal posterior to the orbit. The posterodorsal margin of the jugal contacts the anteroventral margin of the preoperculum (PoP). The dermosphenotic extends quite far back dorsoposteriorly suturing to the dermohyal (Dhy), and there is no pronounced ventral limb. More anteriorly the dermosphenotic sutures to the preoperculum on its posteroventral margin. In PMO 235.121, the dermosphenotic (and articulated supratemporal (St)) have been displaced ventrally. The supratemporal (Fig. 5C) is elongate, with a notched lateral margin for the dorsal head of the dermohyal, as in C. trailli (Pearson \& Westoll, 1979). It is unclear whether a separate intertemporal was present. A narrow spiracular slit (Spi) is framed by the dermosphenotic and supratemporal. The otic canal (the posterior continuation of the infraorbital canal) travels longitudinally through the supratemporal before entering the dorsal margin of the dermosphenotic and turning sharply ventrally. A series of pores mark the passage of the canal through the supratemporal. There is no evidence of a side branch of the canal on the supratemporal, unlike in Cheirolepis canadensis and C. trailli. Within the orbit are four sclerotic bones, the edges of which are flush against each other. They are convex in shape (concave viscerally) and strongly curved to surround the eyeball.

Cheek region. - The check bones consist of the operculum (Op), preoperculum, dermohyal, accessory operculum (aOp) and the quadratojugal (Qj). The preoperculum is a long oval bone with a maximum width/height ratio of about 4.3. As stated above, the anteriormost part of the ventral margin of the preoperculum is sutured to the jugal. The posterior end of the ventral margin is sutured to the quadratojugal, but most of the ventral margin is sutured to the maxilla. The dorsal margin of the preoperculum is sutured to the accessory operculum posteriorly, the dermosphenotic anteriorly and the dermohyal medially. Posteriorly, the preoperculum has a very small connection to the suboperculum (Sop) between the quadratojugal and accessory operculum. The accessory operculum is a triangular bone wedged between the operculum dorsally and the preoperculum ventrally. Its posterior margin is sutured to suboperculum except for a very small suture ventrally to the angular (Ang). The operculum is a long oval bone which is more tapered at the anterior end; maximum width/height ratio of about 3.6. The ventral margin contacts the dermohyal anteriorly and the accessory operculum posteriorly. The suboperculum contacts the posterior of the operculum. An additional dermal bone of uncertain identity is preserved within the second specimen, displaced between the jugals. It is approximately the maximum length of the jugal and has a deep ridge on its visceral surface, making it almost triangular in cross section.

Jaws and teeth. - The maxilla is very long with a width/height ratio of around 4.8. The bone is subrectangular with a long narrow suborbital ramus. A medial shelf runs along the ventral margin of the maxilla (Figs. $3 C \& 5 \mathrm{I}$ ). There are two rows of teeth on the occlusal surface, both of which have frequent rounded empty sockets indicating tooth replacement (Fig. $5 \mathrm{H}, \mathrm{I}$ ). A small replacement tooth is visible in one socket (Fig. 5H). The dermal ornament along the ventral edge of the maxilla is in places pointed and 'tooth-like' in appearance. The occlusal median surface has regularly spaced large teeth (Figs. 4A \& 
$5 \mathrm{E}$ ), which are higher and more slender than those of Cheirolepis canadensis (Arratia \& Cloutier, 1996, fig. 11B) and Cheirolepis trailli (Pearson \& Westoll, 1979, pl. IIA). Posteriorly, it is difficult to see the large teeth due to overlap with the dentary, but there is no indication that they do not continue to the posterior end; the posterior portion of the maxilla in PMO 235.121 bears a single row of large teeth. There are no teeth medial to the large tooth row in PMO 235.121, although this area is buried in rock in the holotype. The dentary is very long with a width/height ratio of 5.8, tapering somewhat anteriorly. The teeth are borne on a medial shelf and arranged in the same pattern as on the maxilla, with the larger teeth on both bones generally curving slightly medially. A long angular, over a third of the length of the dentary, is visible in PMO 235.121, and is overlapped by a smaller surangular (San; Fig. 3A). The latter bears an unornamented area for overlap by the maxilla. The mandibular canal runs along the ventral margin of the angular before passing into the dentary and immediately angling anterodorsally (Fig.5J). Alittlewaybefore the dorsal margin of the dentary, the canallevels offand continues anteroventrally, exiting the bone out of its anterior margin. There are three coronoids (Cor), each of which sat on the medial shelf of the dentary (Fig. 5E). The anterior coronoid is the largest, and all three are covered in pointed and posteriorly curving teeth. The largest tooth row is along the medial margin, and empty tooth sockets are present (Fig. $5 \mathrm{H}$ ).

Branchial region. - The suboperculum is subrectangular in shape. The dorsal margin contacts the operculum and the ventral margin contacts the dorsal-most branchiostegal ray (Brr). The anterior margin of the suboperculum is strongly curved, articulating with the accessory operculum for most of the anterior length except for a short contact with the quadratojugal at the ventral corner. The angular is a narrow and tall oval shape. It sits between the branchiostegal rays and the dentary, and its dorsal corner is sutured to the quadratojugal, preoperculum, accessory operculum and suboperculum. The branchiostegal rays are long and thin and number at least eight. Anteriorly they are articulated to the angular except the lower most ventral ones which are sutured to the dentary.

Ornament. - The dentary, possible parietal (?Pa) and possible postparietal (?Ppa) are ornamented with very short ridges and tubercles. Ridges are more elongate on the maxilla, mainly oriented antero-posteriorly over most of the plate and following its anterior margin anteroventrally. Ridges are short but more sinuous on the jugal and preoperculum, and almost concentric on the dermosphenotic. All the ridges and tubercles are ornamented with numerous subparallel oblique ridges. CT data show that small pores are typically present between the tubercles and ridges, and horizontal canals connect these pore cavities within the dermal bone to form a pore canal network. This is also seen in specimens of Cheirolepis trailli from Edderton, Cromarty and Achanarras (Lu et al., 2016, fig. 3).

Postcranial morphology. - Of the shoulder girdle only the top of the cleithrum is preserved in the holotype (Fig. 1A). It is similar to that of other Cheirolepis species in having a thin tapering dorsal end. No other elements of the shoulder girdle are preserved in the holotype. Parts of the shoulder girdle (as well as the operculogular system) are preserved in the second specimen but have been displaced and compressed and are not possible to model out individually.

Only the pectoral and pelvic fins are preserved. The pectoral fin is very broad, although this might be exaggerated by superposition of the left over the right fin. The distal end of the fin is off the edge of the slab. The fin exoskeleton comprises rows of short lepidotrichia. These are ornamented with up to ten subparallel oblique ridges (Fig. 6A, B). The anterior end of the pelvic fin base is posterior to the pectoral fin, at over a head length back from the jaw articulation. The anterior edge of the pelvic fin is gently convex, but the posterior edge is not preserved as it would have been off the edge of the slab. However, the fin base appears to be a similar length and position as that of Cheirolepis trailli (Pearson \& Westoll, 1979, fig. 21A) and markedly shorter than that of Cheirolepis canadensis (Arratia \& Cloutier, 1996, fig. $3 \mathrm{~A})$. Like the pectoral fin, the distal end of the pelvic fin extended off the edge of the slab and is not 

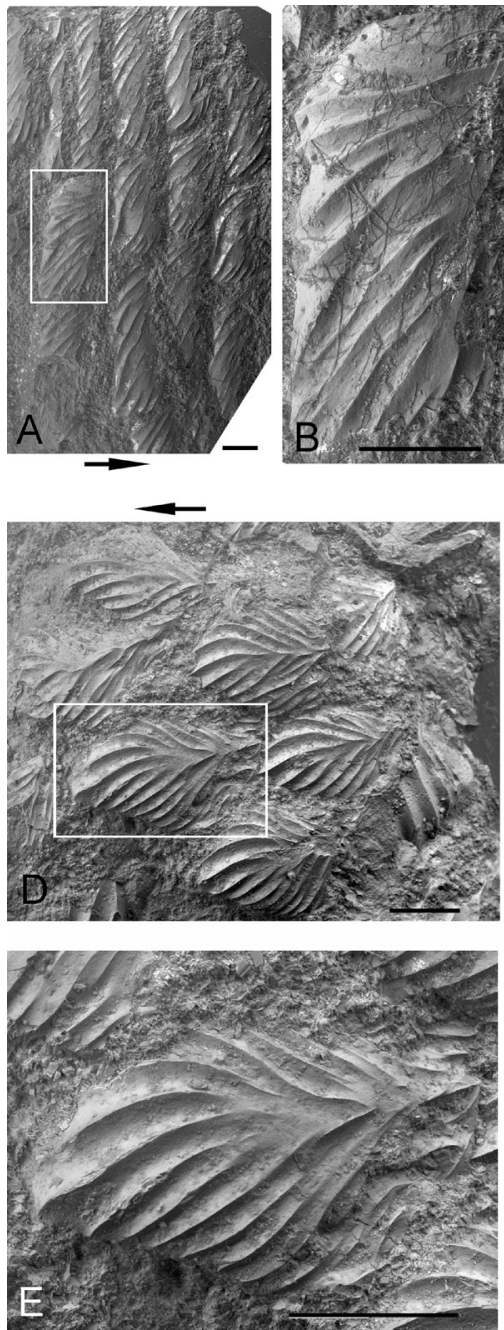

Figure 6. Cheirolepis jonesi PMO 235.120/01-06 the holotype from Estheriahaugen North. Lepidotrichia and scales. (A-C) Lepidotrichia of the pectoral fin. (A-B) PMO 235.120/01. (A) crowns of articulated lepidotrichia. (B) close-up of lepidotrichium in rectangle in A. (C) PMO 235.120/04 transverse section through articulated lepidotrichia. (D-I) Scales posterior to the pectoral fin. (D-F) PMO 235.120/02. (D) articulated scale patch. (E) close-up of scale in rectangle in D. (F) scale with subparallel ridges. (G) PMO 235.120/03, scale with subparallel ridges. (H, I) vertical transverse sections through scales. (H) PMO 235.120/05. (I) PMO 235.120/06. Scale bars $=0.5 \mathrm{~mm}$. Arrows indicate anterior direction.

preserved. The lepidotrichia show the same ornament as the pectoral fin lepidotrichia. The histological structure of the lepidotrichia is identical to that of the same elements in C. canadensis (Zylberberg et al., 2016 , fig. 3), with a very deep bone base having an apophysis that contacts the adjacent lepidotrichium, and a crown comprising superposed zones of dentine and ganoine (Fig. 6C).

The scales have a diagonal length c. 0.5 to $0.7 \mathrm{~mm}$. The crown has up to 15 smooth sharp oblique ridges that extend beyond the posterior corner of the base. On larger scales the ridges tend to converge posteriorly (Fig. 6D, E) whereas on other scales, usually with fewer ridges, they stay subparallel (Fig. 6F, G). Like the lepidotrichia, the scales (Fig. 6H, I) have the same basic histological structure as in Cheirolepis canadensis (Gross, 1947, pl. 6, figs. 11-20; 1953, fig. 10C; Pearson \& Westoll, 1979, fig. 15a, b, d, f, g; Zylberberg et al., 2016, fig. 2B) and also Cheirolepis trailli (Gross, 1953, fig. 10A, B; 1966, fig. 3E, F; Pearson \& Westoll, 1979, fig. 15c,e), Cheirolepis gaugeri (Gross, 1973, fig. 33A-D), and Cheirolepis gracilis (Gross, 1973, fig. 34D-G). They have a cellular bone base and a crown formed of dentine and ganoine layers, with dentine restricted to the oldest growth zones and the lateral margins of younger growth zones. The main difference between species is the number of layers, with the larger Cheirolepis jonesi scales having 10 or more crown growth zones (Fig. 6H, I). The histological structure of Cheirolepis aleshkai and Cheirolepis schultzei scales is unknown. 


\section{Comparison with other Cheirolepis species}

Most species of Cheirolepis known from articulated specimens have a similar skull morphology (Fig. 7) and differences are mostly based on the relative dimensions of the bones. The problem with this approach is that there can be a considerable variation in bone dimensions within a given species. However, the following characters distinguish Cheirolepis jonesi nov. sp. from the other Cheirolepis species. It differs from Cheirolepis schultzei and Cheirolepis canadensis in having a proportionally longer accessory operculum and correspondingly shorter dermohyal, as well as a longer premaxilla and proportionally larger quadratojugal. There is a greater length of the jugal under the orbit in C. schultzei and $C$. canadensis than in $C$. jonesi. The elongate dermosphenotic with its irregular dorsal and ventral margins and long spiracular slit resembles that of Cheirolepis trailli, albeit with a shorter ventral limb. The rostral bones of $C$. jonesi also differ from those of $C$. schultzei and $C$. canadensis, but as stated above the preservation in $C$. jonesi is not particularly good in this area. $C$. jonesi is more similar to $C$. trailli, and the premaxilla of $C$. jonesi resembles that of $C$. schultzei and $C$. trailli in extending some way posterior to the anterior margin of the maxilla. $C$. jonesi differs from all other Cheirolepis species in the narrow anterior end of the dentary and the relatively large quadratojugal located at the posterior dorsal corner of the maxilla, and the absence of a side branch of the otic canal on the supratemporal. Also, the main teeth on the maxilla and dentary are relatively higher and slenderer than those of the other species.

The scales of Cheirolepis jonesi (Fig. 4D-H) are very similar in both morphology and histology to those of Cheirolepis canadensis (Gross, 1966, fig. 3C, D; Pearson, 1982, fig. 1D; Zylberberg et al., 2016, fig. 2A), Cheirolepis trailli (Gross, 1966, fig. 3E, F; Pearson, 1982, fig. 1C) and Cheirolepis gaugeri (Gross, 1973, pl. $35.9,14)$. Diagonal length of illustrated scales of all species is c. $0.5 \mathrm{~mm}$. Gross (1973) described scales of $C$. gaugeri as smaller than those of $C$. trailli, but at least some are of a comparable size (Gross, 1973, pl. 35.12, 14). C. gaugeri scales have 6-8 ridges on the crown, which is within the range seen in $C$. jonesi as well as $C$. canadensis. However, some of the $C$. jonesi scales have a diagonal length c. $0.7 \mathrm{~mm}$
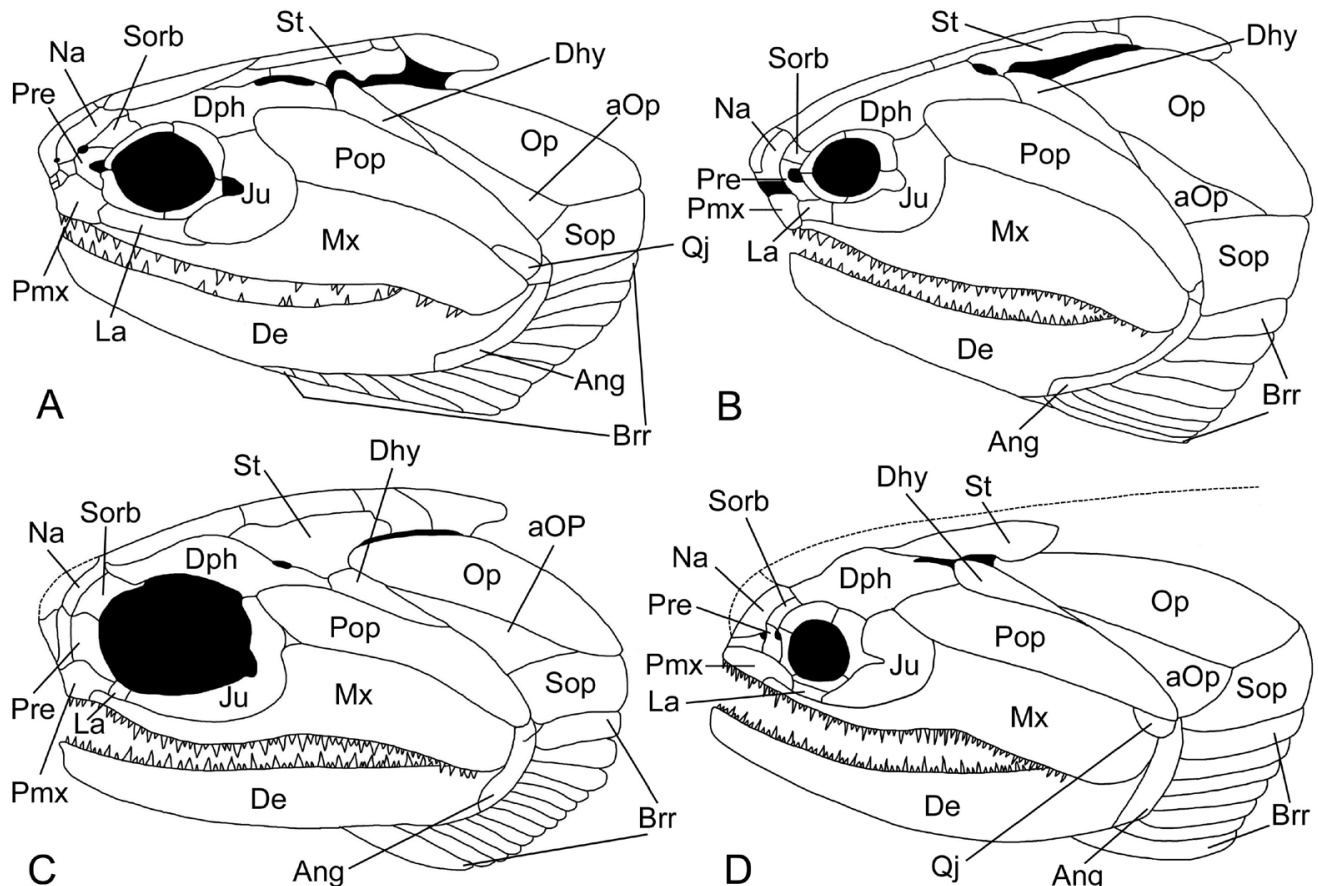

Figure 7. Articulated heads of Cheirolepis species. (A) Cheirolepis trailli (slightly modified after Pearson \& Westoll, 1979). (B) Cheirolepis canadensis (slightly modified after Arratia \& Cloutier, 1996). (C) Cheirolepis schultzei (slightly modified after Arratia \& Cloutier, 2004). (D) Cheirolepis jonesi. Ang - angular, aOp - accessory operculum, Brr - branchiostegal rays, De - dentary, Dhy - dermohyal, Dph - dermosphenotic, Ju - jugal, La - lacrimal, Mx - maxilla, Na nasal bone, Op - operculum, Pmx - premaxilla, Pop - preoperculum, Pre - preorbital bone, Qj-quadratojugal, Sorb - supraorbital bones, Sop-suboperculum, St-supratemporal. 
(Fig. 4D), larger than the average size in all species. Clearly there is variation in size and ornament, including the number and orientation of ridges, over different areas of the body. Pearson (1982) distinguished the scales of $C$. trailli from those of $C$. canadensis by their having longer spines (i.e., posterior crown ridge denticulations). The scales on $C$. schultzei are very poorly preserved, but appear to be c. $0.4 \mathrm{~mm}$ wide with $4-8$ crown ridges. The crown can extend up to a length of the base beyond its posterior corner (Reed, 1992, text-fig. 1). Scales of Cheirolepis gracilis are easiest to distinguish from the other species based on their finely ribbed sculpture comprising 12-20 narrow, bifurcating ridges (Gross, 1973, pl. 36, figs. 2-6). The new scale-based species Cheirolepis aleshkai Plax, 2020 from the Eifelian Osveya Regional Stage of Belarus comprises scales of a similar size to those of C. jonesi, but the crown ridges are parallel to each other on separate crown areas rather than tending to converge posteriorly as in $C$. jonesi, the crown barely extends beyond the base posteriorly, and the base lacks a well-developed keel.

\section{Conclusions}

Cheirolepis was described by Giles et al. (2015) as the earliest unequivocal actinopterygian, based on numerous phylogenetic analyses of early gnathostome relationships. Cheirolepis jonesi nov. sp. differs from the other species in the relative dimensions of the plates of the head and the nature of the teeth. The earliest Cheirolepis species known is the scale-based Cheirolepis gracilis, present at the base of the Eifelian in Estonia and the middle Eifelian in Belarus (Mark-Kurik, 2000). Of the other scale-based species, Cheirolepis aleshkai is from the low-middle Eifelian of Belarus and Cheirolepis gaugeri is present in the middle Givetian of Estonia and Belarus (Mark-Kurik, 2000). The earliest Cheirolepis species known from articulated remains is Cheirolepis trailli, from the upper Eifelian of the Orcadian Basin of Scotland. $C$. jonesi is the second oldest Cheirolepis species known from articulated remains and is present at the base of the late Givetian of Spitsbergen (Newman et al., 2019). Cheirolepis schultzei is the third oldest Cheirolepis species known from articulated remains and is present in the uppermost Givetian of Nevada, USA (Schultze, 2010). Cheirolepis canadensis is the youngest Cheirolepis species and is present in the early Frasnian of Canada (Arratia \& Cloutier, 1996). Most of the species are considered to have lived in a marine or marginal marine environment. The only species unequivocally non-marine is $C$. trailli. However, as discussed by Newman \& Trewin (2008), most of the fish species in the Orcadian Basin were probably marine forms that migrated from the Baltic Region. A biostratigraphic column of the five species is given in Fig. 8. Looking forward, the Estheriahaugen North outcrop is still productive, and it is hoped that further collecting will produce more material of $C$. jonesi which will allow a more detailed description of the species. Also, the fieldworkers acknowledged below have several tons of unprepared nodules still to prepare and analyse.

\begin{tabular}{|c|c|c|}
\hline \multicolumn{2}{|c|}{ Middle Devonian } & Late \\
\hline Eifelian & Givetian & Frasnian \\
\hline $\begin{array}{l}\text { Cheirolepis gracilis } \\
\text { Cheirolepis aleshkai } \\
\text { Cheirolepis trailli }\end{array}$ & Cheirolepis schultzei & \begin{tabular}{|c} 
\\
\\
Cheirolepis \\
canadensis
\end{tabular} \\
\hline
\end{tabular}


Acknowledgements. MJN would like to thank Professor John Marshall (University of Southampton) and Dr Chris Berry (Cardiff University) for inviting him to do the original fieldwork in Mimerdalen. MJN would also like to thank fellow fieldworkers, Roger Jones (London), Patrick and Robert Gavin (Glasgow), Tormi Tuuling (Tallinn), John Armstrong (Edinburgh), Chris and Alex Moore (Charmouth) and Steven Waters (Dollar, Clackmannanshire) for their hard work in the field. MJN would also like to thank the staff at the Tulip Hotel in Pyramiden for all their assistance, and Sergey Chernikov of the Grumant Arctic Travel Company for help with logistics. SG would like to thank Vincent Fernandez and Brett Clark for assistance with CT scanning. The authors thank would also like to thank Dr Mark Mehle (Cleveland) for donating PMO 235.121 for use in this study. We would like to thank the two reviewers Brian Choo (Flinders University) and Rodrigo Tinoco Figueroa (University of Michigan) for their insightful comments that greatly improved the article. CJB acknowledges the support of the Queensland Museum. SG was supported by a Royal Society Dorothy Hodgkin Research Fellowship.

\section{References}

Agassiz, J.L.R. 1833-1843: Recherches sur les Poissons fossiles. Imprimerie Petitpierre. Neuchâtel, 1420 pp. https://doi.org/10.5962/bhl.title.4275.

Arratia, G. \& Cloutier, R. 1996: Reassessment of the morphology of Cheirolepis canadensis (Actinopterygii). In Schultze, H.-P. \& Cloutier, R. (eds.): Devonian fishes and plants of Miguasha, Quebec, Canada, Verlag Dr Frederich Pfeil, München, pp. 165-197.

Arratia, G. \& Cloutier, R. 2004: A new cheirolepidid fish from the Middle-Upper Devonian of Red Hill, Nevada, USA. In Arratia, G., Wilson, M.V.H. \& Cloutier, R. (eds.): Recent advances in the origin and early radiation of vertebrates, Verlag Dr Friedrich Pfeil, München, pp. 583-598.

Cope, E.D. 1887: Geology and palaeontology. American Naturalist 1887, 1014-1019.

https://doi.org/10.1086/274597.

Giles, S., Coates, M.I., Garwood, J., Brazeau, M.D., Atwood, R., Johanson, Z. \& Friedman, M. 2015: Endoskeletal structure in Cheirolepis (Osteichthyes, Actinopterygii), an early ray-finned fish. Palaeontology 58, 849-970. https://doi.org/10.1111/pala.12182.

Gross, W. 1947: Die Agnathen und Acanthodier des Obersilurischen Beyrichienkalks. Palaeontographia A 96, 91-161.

Gross, W. 1953: Devonische Palaeonisciden-Reste in Mittel- und Osteuropa. Palaeontologische Zeitschrift 27, 85-112. https://doi.org/10.1007/BF03041836.

Gross, W. 1966: Kleine Schuppenkunde. Neues Jahrbuch für Geologie und Paläontologie Abhandlungen 15, 29-48.

Gross, W. 1973: Kleinschuppen, Flossenstacheln und Zähne von Fischen aus europäischen und nordamerikanischen Bonebeds des Devons. Palaeontographica A 142, 51-155.

Huxley, T.H. 1880: On the applications of the laws of evolution to the arrangement of the Vertebrata and more particularly of the Mammalia. Proceedings of the Zoological Society of London 43, 649-662. 
Lu, J., Giles, S., Friedman, M., den Blaauwen, J.L. \& Zhu, M. 2016: The oldest actinopterygian highlights the cryptic early history of the hyperdiverse ray-finned fishes. Current Biology 26, 1602-1608. https://doi.org/10.1016/j.cub.2016.04.045.

Mark-Kurik, E. 2000: The Middle Devonian fishes of the Baltic States (Estonia, Latvia) and Belarus. Courier Forschungsinstitut Senckenberg 223, 309-324.

Meunier, F.J., Otero, O. \& Laurin, M. 2018: Histological study of the jaw teeth in the Devonian actinopterygian Cheirolepis canadensis (Whiteaves). Cybium 42, 67-74.

https://doi.org/10.26028/cybium/2018-421-005.

Newman, M.J. \& Trewin, N.H. 2008: Discovery of the arthrodire genus Actinolepis (clad Placodermi) in the Middle Devonian of Scotland. Scottish Journal of Geology 44, 83-88. https://doi.org/10.1144/sjg44010083.

Newman, M.J., Burrow, C.J. \& den Blaauwen, J.L. 2019: The Givetian vertebrate fauna from the Fiskeklofta Member (Mimerdalen Subgroup), Svalbard. Part I. Stratigraphic and faunal review. Part II. Acanthodii. Norwegian Journal of Geology 99, 1-16. https://doi.org/10.17850/njg99-1-01.

Newman, M.J., Burrow, C.J. \& den Blaauwen, J.L. 2020: A new species of ischnacanthiform acanthodian from the Givetian of Mimerdalen, Svalbard. Norwegian Journal of Geology 99, 619-631.

https://dx.doi.org/10.17850/njg99-4-4. '

Pander, C.H. 1860: Über die Saurodipterinen, Dendrodonten, Glyptolepiden und Cheirolepiden des Devonischen Systems. Kaiserlichen Akademis des Wissenschaften, St Petersburg, 100 pp.

Pearson, D.M. 1982: Primitive bony fishes, with especial reference to Cheirolepis and palaeonisciform actinopterygians. Zoological Journal of the Linnean Society 74, 35-67. https://doi.org/10.1111/j.1096-3642.1982.tb01140.x.

Pearson, D.M. \& Westoll, T.S. 1979: The Devonian actinopterygian Cheirolepis Agassiz. Transactions of the Royal Society of Edinburgh 70, 337-399. https://doi.org/10.1017/S0080456800012850.

Plax, D. 2020: A new species of the actinopterygian fish (Osteichthyes, Actinopterygii) from the Eifelian deposits of the Vileyka Buried Ridge (Belarus). Lithosphere 52, 68-73.

Reed, J.W. 1992: The actinopterygian Cheirolepis from the Devonian of Red Hill, Nevada, and its implications for acanthodian-actinopterygian relationships. In Mark-Kurik, E. (ed.): Fossil fishes as living animals, Academia 1. Academy of Sciences of Estonia, Tallinn, pp. 243-249.

Schultze, H.-P. 2010: The late Middle Devonian fauna of Red Hill I, Nevada, and its paleobiogeographic implications. Fossil Record 13, 285-295. https://doi.org/10.1002/mmng.201000001.

Schultze, H.-P. 2015: Scales, enamel, cosmine, ganoine, and early osteichthyans. Comptes Rendus Palevol 15, 83-102. http://dx.doi.org/10.1016/j.crpv.2015.04.001.

Whiteaves, J. 1881: On some remarkable fossil fishes from the Devonian Rocks of Scaumenac Bay, P.Q., with a description of a new genus and three new species. Canadian Naturalist 10, 27-35.

Zylberberg, L., Meunier, F.J. \& Laurin, M. 2016. A microanatomical and histological study of the postcranial dermal skeleton of the Devonian actinopterygian Cheirolepis canadensis. Acta Palaeontologica Polonica 61, 363-376. http://dx.doi.org/10.4202/app.00161.2015. 